\title{
Feature Analysis of the Social Media
}

\author{
$\mathrm{Hua} \mathrm{Hu}$ \\ School of Information Management \\ Wuhan University \\ Wuhan, China \\ henryhu@whu.edu.cn
}

\author{
Ding Lin \\ School of Marxism \\ Central China Normal University \\ Wuhan, China \\ dinglin96@139.com
}

\begin{abstract}
This paper studied the history of social media and the development of social media features. Then it discovered the significant features of social media by applying the information science theory. After that the paper found the relationship between social media features change and technology development. Finally, we predicted the trends of the social media features and infer the direction of social media technologies.
\end{abstract}

Keywords- Social media; historical changes; feature analysis; technical challenges

\section{INTRODUCTION}

Social media has become an essential part of life of hundreds of millions people worldwide. Whether we want to find good books or popular movies, life issues or seek the help of medical problems, we can turn to social media. Social media has changed people's social habits. It is becoming a hotspot and trends of the network technology. Feature analysis of social media has a broad social background, economic background and technical background.

At present, foreign scholars have a few researches on the characteristics of social media from a multidisciplinary, such as Antony Mayfield etc. who summarized the performance characteristics of social media [1]. Psychological feature analysis has been implemented on social media by Andreas M. Kaplan [2]. Social media's characteristics were studied by W. Glynn Mangold [3]. There are some scholars make the feature summary of specific social media sites $[4,5]$. While domestic scholars mainly studies social media features from the perspective of communication, such as Sun Nannan, You Hengzhen, Li Linrong, which means the research perspective is relatively simple.

The researches of the characteristics of social media are mostly by induction of the current study. And the characteristic of social media in different periods has the different present style. Therefore, this paper analyzes the development of social media, then study the evolution of social media features based on the information theory perspective, and want to find the relationship between the characteristic changes and the technical changes. So we can infer the characteristic factors and trends of social media which can provide guidance to social media technology.

\section{ANALysis of Social Media DeVELOPMENT}

Social media are constantly changing with the changing of its features. From Figure 1 we can see that the development of social media with a certain regularity. Combined with the study of the Ellison and related literature [6], the development of social media can be divided into four stages, early stages, exploratory stage, growth stage and transition stage.

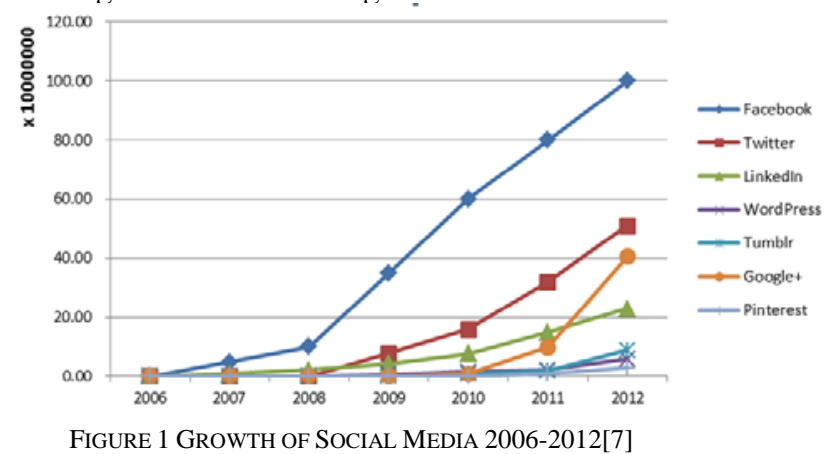

\section{A. Early Stages of Social Media}

Social media birthed with the presentation of computer technology and network technology. It comes from the socialization of the network media which based on the theory of "Six Degrees of Separation", and realize the interpersonal communication on the internet [8].

Social media earliest origins can be traced back to 1971 when the first email was born from ARPA, which is the first interpersonal communication through the network. After that, the prototype of social media was made by Tom Truscott and Jim Ellis from Duke University in 1979 named Usenet which allowed users to upload articles and news to no administrator, no centralized server newsgroups. This is the predecessor of "RSS". Soon after the Usenet, BBSs (Bulletin Board Systems) is also developed by two computer enthusiasts to notify friends to meetings and share information [9].

The feature of social media in this stage does not exceed the traditional media, because it only used among professional computer technician in limited range of LAN for information exchange. This means social media is 
complicated to use, and can't support the information sharing in big range easily or rapid.

After TCP / IP is introduced to solve the heterogeneous network terminal information resource sharing, social media information tends to concentrate which improve the speed of information interaction. Since early 1990s, there are many similar social media network services birth, such as The WELL (The Whole Earth Lectronic Link) system and GEnie system.

\section{B. Exploratory Stage of Social Media}

World Wide Web birth means that the global Internet era comes. WWW technology integrates information together over the world, so social media can contact anywhere and this help information organization more convenient. Affected by this change, internet forums replaced of Usenet and BBSs which have the similar functions with the current social media.

Six Degrees is the first real sense of social media birthed in 1997. It allows its users to create profiles, invite buddies, organize groups, and surf other user profiles. The integration of the social media functions supports the user interpersonal communication with others. In the same year, Blog also formally proposed by the Jorn Barger.

In exploration stage, WWW technology effectively centralizes the social media information to a huge network. Information exchange all over the world is achieved, that means social media attract more users. The popularity of computer and network technology reduces the barriers to applications of social media. In this case, a large number of social media information was generated and discrete distributions in the Internet. Therefore there needed the effective methods of information organization and management to solve the expanding of social media information. The application of directory search engine supported the collection, query and use of the social media information. But with the limitations of directory search engine technology, user-generated content increased so fast that it was more difficult to find the information we need. This problem cause the difficultly explore stage of social media.

\section{Growth Stage of Social Media}

WEB2.0 technology emerged after Blog, which changed the two side communication to multi-party online and greatly reduced the time and costs of social media communication. The emergence of Google and Pagerank algorithm known as the development of information retrieval technology support the user to utilize and organize the social media information effectively. Meanwhile, the search engine technology helped social media to achieve profit model. These developments bring an opportunity to the stage, which has emerged a series of social media, such as the most famous online encyclopedia "Wikipedia", famous photo blog site "Fotolog", most widely used social bookmarking site "Del.icio.us", famous world of virtual reality site "Second Life", well-known social networking media "MySpace", the world's largest social news site "Digg", worldwide use sharing site
"Flickr" and so on. In 2004, the social media site Facebook.com also set up. After two redesigned, Facebook rapid grows as an integrated community of users worldwide. Until today, Facebook is still the most typical social media and research for scholars worldwide.

In the process of development of social media, Tencent QQ in China, the world's largest instant messaging service platform and largest online community service platform integrate the social media elements to chat platform in 2006, and injected the social service into the world's largest Internet population.

Internet users increase with the development of computer technology and network technology. The number of the increase can't meet with explosive growth of social media sites because of the WEB2.0. Finally there would form a competition for limited users. These competitions bring a rich diversity of social media and make the social media distribution. In this case, some social media try to find other way.

\section{Transition Stage of Social Media}

The opportunity of social media is the mature of mobile terminals and mobile technology, which is the key technical factor to promote the transformation of social media.

Twitter was the first to change, which initially only provide "use text messaging to tell friends what they are doing". But with the outstanding characteristics from the combination of the mobile terminal and communication technology, Twitter rapidly developed as a symbol of real time social media. 2007 Apple Inc. and Google Inc. had introduced their own mobile operating system which can help social media transplant to mobile terminals [10].

Social media patent explosively grow in 2007 shown in Figure 2. We can find the emergence of mobile terminal and mobile technology creates a large number of social media users. These technologies had changed the users' behavior, so they can communicate with others through the mobile terminal platform anytime and anywhere. This will greatly enhance the speed of social media information exchange, and make social media more popular and widespread.

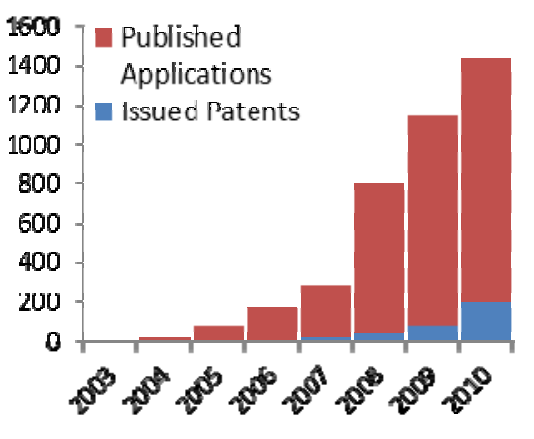

FigURe 2 Growth of Social Media Patents [11]

With the rapid development of mobile terminals, location based services (LBS) technology has gradually 
matured and means mobile social media was born. This technology adds a dimension to the social media which is "location-aware"[12]. Social media information not only can be integrated by the topic, users, social, but also by the location [13]. Users can take advantage of LBS services to get more targeted information services.

Since then, almost all of the social media are integrated into the mobile terminal platform, and the mobile terminal brings ease of use, integration and timeliness effectively integrated into the social media. This comes with the big data, which is the challenge for further development of social media.

\section{FEATURE ANALysis OF SOCIAL MEdiA}

Social media has many advantageous features over traditional media. These features are derived from the social media technology. There are four characteristics, along with the development of social media continue to strengthen. This paper apply intelligence theory to deconstruct social media features, because social media is a part of information chain [14].

\section{A. Integration}

The integration is mainly manifested in the integration of hundreds of millions of dispersed users with different characteristics. Social media connect users around the world, so that they can exchange and share information with the same platform. Integration is the present of a small world theory and scattering distribution principle. This feature is from information integration technology such as the TCP / IP protocol and WWW technologies which appearing in early and exploratory stage of social media, enhanced with the development. Information integration technology provides an effective guarantee for heterogeneous information, platforms and terminals to achieve interconnection, this shorten the shortest path of information, and better support the user to maintain "strong ties" and expanding the "weak relations" of social media. So the small world phenomenon is apparent. Integration of users and information resources shows Matthew phenomenon in social media.

\section{B. Time Effectiveness}

The delay in Social media information exchange can be ignored. User of social media can send and receive information immediately whenever they want, which means information exchange synchronization and user can fast access to the required information. Time effectiveness is a measure of an important indicator of intelligence value. The aging of intelligence and attenuation of the value is because of the lack of time effectiveness. Because of it social media information is high-value, which will widely attract users. This is the advantages characteristic factors. Computer technology, mobile terminal technology and network technology will be high-speed, broadband, intelligent, easy direction, so as to continuously enhance the time effectiveness of social media. This process will throughout the development of social media.

\section{Least Effort}

Social media is almost open and free to use, users do not need special skills or special training can easily use social media. So the user will make least effort to get and utilize the information and knowledge in social media. This is the performance of the least effort principle of Information Science. All the technology used in social media is to help user make least effort to get and utilize the information, and which is the driver of the social media. The least effort of social media just follows the Zipf's law which is the basic principles of information science. This means social media will receive two opposite forces-"single force" and "diverse force." The role of these two forces manifested in one hand we hope the information in social media kept short and simple so it is easy to manage and use. On the other hand we want social media information detailed and rich so we can get more value. Social media information retrieval techniques can enhance the social media "Single force" to improve the efficiency of information access and use. This will break the equilibrium state of development, making social media from the exploration stage to the growth stage.

\section{Orderliness}

The dynamic and the public of social media makes social media ordered. As we know, because of the WEB2.0 social media is open and dynamic. If we consider social media as a system, this will match the principle of information science in the "dissipative structures" theory "an open and dynamic system will spontaneously transform form disordered and chaotic state to a new kind of space and feature ordered state. There are mass user and information in social media, so this will provide a lot of entropy stream into the knowledge system of social media, and which will make the social media system to reach equilibrium or form a new knowledge system. So the accumulation, regeneration and aging of social media intelligence, compared to traditional media, is more quickly. This could also explain the chaos and order phenomenon of social media, reflecting the self-organization mechanism of social media information. Because social media users can edit and revise information, the wrong and useless information in social media will be filter out. This use of human's creativity and the regular of intelligence itself to makes the whole social media information more valuable.

\section{SOCIAL MEDIA TRENDS AND TECHNOLOGY CHALLENGES}

The feature of social media changes with the development of social media. Because of these features, social media was widely used and the information can be so rich, real and has great value. Based on the regular of the four characteristics of social media, the paper predicts the trends of social media. Some trends can be found around us now, it is slowly change the social media and bring the new technical challenges. 


\section{A. Overall trends}

The orderliness of social media will complete the organizational system of social media. Currently social media has served the realm which the traditional media can't involve, and developed specialization and segmentation. This is the evolution of social media to cover the blank. This trend will ultimately lead to social media for comprehensive coverage of all areas. The development of least effort will continue to expand the use group of social media, such as the elderly or people with disabilities (especially the blind) etc. who can't properly use social media. There are already some services for the elderly, while many social media services for the disabled are being implemented, such as the cooperation projects between Facebook with American Foundation for the Blind. This will result in a phenomenon of the scattering distribution and unstructure of information and increase semantic complexity of information, which requires to improve capabilities of the natural language processing and irregular content processing.

\section{B. Convergence trends}

The user and information will be more concentrate because of the integration and the least effort of social media. This phenomenon would make the convergence of the information, media and no-media in the social media. As we know social media has be a significant role in the U.S. president election which integrates the voters, media and government. This convergence trend is more obvious in such as Facebook, Twitter, Sina and other social media portals. They are almost integrated all media functions such as social media, news, games, video sharing, photo sharing and e-commerce etc. together. This will result the big data phenomenon in social media. Convergence trend requires us to integrate information from different sources and structures and achieve the integration of variety of formatted documents, process and organize of multimedia files, multilingual information, and integrate the structured data, semi-structured data and unstructured data. This is the new challenges for information integration and retrieval technology

\section{Value Trends}

According to the 2012 Edelman's global confidence survey [16], part of social media users trust social media even more than the experts. Blog, podcasting can be referenced literature sources of the American Psychological Association as academic standard, which are illustrated the value of social media in a wide range which is the performance of the orderliness. Information will accumulate in social media because of the integration, least effort and timeliness features. The value of information will concentrate in social media because of the orderliness. Finally social media will form a huge knowledge base. How to efficient and low cost manage and use of social media information, will be the next orientation. Current application keyword matching search engine has been unable to meet the users' needs of the social media, while the use of the mobile terminal needs new search engines technology. So how to directly provide the answer to the users' question has become the trend of retrieval services. Computer will not only need to understand the user's search needs to identify all relevant content, but also to analyze the retrieve results, filtering out unwanted information, integrate association information, which will gives a simple and targeted answer to the user's question. It is the new challenges for information retrieval and semantic information analysis technology.

\section{CONCLUSION}

In recent years, social media fascination in the development and evolution of the Internet increasingly been demonstrated and everything is about social media. Academic research on social media has become the hot spots of information management and information technology. This study combines the technical context of social media and social media history, divided social media development into infancy, exploration, growth and transition stage, and analyzed technology, feature changes and typical model of social media. Secondly, the paper deconstructs all stages of development features of social media based on the information science theory, then find out the four feature factors: integration, timeliness, least effort and orderliness, and analyze the relationship between the social media features and technology relationship. Finally, the paper predict the trends of social media which is overall trend, convergence trend and value trend, infer social media will be faced with the challenge of the technology of information integration, information retrieval, information analysis, semantic processing and artificial intelligence.

\section{ACKNOWLEDGMENT}

This work was supported by Natural Science Foundation of China," Social Media Integration retrieval and semantic analysis method”, grant number 71273194.

\section{REFERENCES}

[1] Antony Mayfield, "What is Social Media," http://www.au.af.m il/au/awc/awcgate/jfq/mayfield_strat_for_soc_media.pdf

[2] Kaplan Andreas M, Haenlein Michael, "Users of the world, u nite! The challenges and opportunities of social media," Busin ess Horizons, vol. 53, Jan. 2010, pp. 59-68.

[3] Mangold W G, Faulds D J, "Social media: The new hybrid e lement of the promotion mix," Business horizons, vol. 52, Jul y. 2009, pp.357-365.

[4] Carter B, Levy J, Facebook Marketing: Leveraging Facebook Features for Your Marketing Campaigns, $1^{\text {st }}$ ed., Que Pub, 20 11.

[5] Chu M, Meulemans $\mathrm{Y} \mathrm{N}$, "The problems and potential of $\mathrm{M}$ ySpace and Facebook usage in academic libraries," Internet R eference Services Quarterly, vol. 13, Feb. 2008, pp. 69-85.

[6] Ellison N B, "Social network sites: Definition, history, and sc holarship," Journal of Computer - Mediated Communication, v ol. 13, Feb. 2007, pp. 210-230.

[7] D.Steven White.Social Media Growth 2006-2012, http://dsteve nwhite.com/2013/02/09/social-media-growth-2006-to-2012/ 
[8] Wang Yihong, "Westerners define interpersonal communication Discrimination," Journalism and Communication Studies. Vol. 4, Feb. 1996, pp.72-80.

[9] Garramone G M, Harris A C, Anderson R, "Uses of political computer bulletin boards," Journal of Broadcasting \& Electro nic Media, vol. 30, Aug. 1986, pp. 325-339.

[10] Sree Sreenivasan, "8 social-media changes since the 2008 elec tions,” http://news.cnet.com/8301-33619_3-57545951-275/8-socia l-media-changes-since-the-2008-elections/

[11] Mark Nowotarski, "Do not Steal My Avatar! Challenges of S ocial Network Patents,” http://www.ipwatchdog.com/2011/01/23 /dont-steal-my-avatar-challenges-of-social-networking-patents/id= $14531 /$.

[12] Lugano G, "Mobile social networking in theory and practice," First Monday, vol. 13, Feb. 2008, pp. 3.

[13] You Hengzhen, "Evolution of Social Media," Beijing Univer sity of Posts and Telecommunications, 2012.

[14] Ma Feicheng, "On the basic principles of Information Science and Theoretical System Construction," Journal of the China Society for Scientific andTechnical Information,vol 26, Feb. 2 007, pp. 3-13.

[15] Edelman, “2012Edelman Trust Barometer," International PR,vo l. 12, Jan. 2012, pp.4-8 